\title{
Market Competition and the Health Composition of Manufactured Food
}

\author{
Stephen F. Hamilton* and Vincent Réquillart ${ }^{\dagger}$
}

September 13, 2016

\begin{abstract}
There has been surprisingly little research to date on the supply-side role of food manufacturers on equilibrium health outcomes for consumers. In this letter we consider an oligopoly model in which food processors choose the health composition of manufactured food. We show that price competition between food processors leads to unhealthy food composition in the market equilibrium, even under circumstances where consumers know the food content is unhealthy. Taxes on manufactured food decrease the healthiness of manufactured foods whenever an improvement in consumer health increases the price elasticity of food demand.
\end{abstract}

Keywords: food design, consumer health, manufactured food, nutritional policies. JEL Classification: I18, L13, Q18.

\footnotetext{
*California Polytechnic State University, USA

${ }^{\dagger}$ Toulouse School of Economics, INRA, University of Toulouse Capitole, Toulouse, France. This paper was written while V. Réquillart was visiting California Polytechnic State University.
} 


\section{Introduction}

While considerable research has been conducted on the health implications of consumer diet and exercise choices, the supply-side role of food processors in composing healthy food items has been largely ignored in the literature. In this letter, we consider incentives for food processors to influence equilibrium health outcomes through endogenous choices of manufactured food composition.

Food processor decisions on manufactured food composition have essential consumer health implications for several reasons. First, manufactured food represents a substantial share of what consumers eat, comprising roughly 70 percent of the diet of U.S. consumers (Warner 2013). Second, technological change has greatly enhanced the capability of food processors to alter food composition, an activity that emerging evidence suggests is an important determinant of consumer health (Monteiro 2009, Moubarac et al. 2013). Third, competitive forces in markets that drive food processors to minimize cost can greatly alter market incentives for healthy food composition. For example, input substitution towards partially hydrogenated oils reduces production cost (Unnevehr and Jagmanaite 2008), allowing food processors engaging in these choices to achieve a lower price point. Such food composition decisions can provide a competitive advantage to individual food processors with adverse consequences for consumer health.

We frame our model of food composition choices by introducing consumers' overall health status as an argument of manufactured food demand. For example, fast food demand may depend on doctors' warnings on health outcomes. Consumer health outcomes, in turn, depend both on the amount of food consumed and on the equilibrium composition of manufactured food products. ${ }^{1}$ Given a large number of manufactured food products available for consumption, consumer health outcomes are determined by the joint consumption of numerous food products, which makes consumer health outcomes a common property resource.

\footnotetext{
${ }^{1}$ Consumer exercise choices, which are also important determinants of consumer health, are outside the scope of the model.
} 
Indeed, food processors have long observed the common property aspect of consumer health outcomes. In Pelman v. McDonald's Corp., McDonald's argued that there was no evidence that obesity-related health problems were caused by McDonald's fast food, as opposed to all the other manufactured foods consumers eat. ${ }^{2}$ In the U.S., for example, the sixteen largest food processing firms in the U.S. together account for only $25 \%$ of U.S. calorie consumption (Slining et al. 2013), making it difficult to pinpoint responsibility for consumer health outcomes on a single firm.

When food composition decisions affect production costs, the incentive for healthy food composition is influenced by the common property element of consumer health. When selecting less costly food composition, an individual food processor receives the entire value of the cost decrease, but shares the burden of the consumer health impact with all food processors through the associated change in aggregate demand. For example, adding salt to processed meats reduces cost (He and McGregor 2009), allowing an individual food processor to capture rents by increasing the salt content of food; however, excessive salt consumption can lead to high blood pressure reports from doctors, reducing consumer demand for all processed meats at once.

In this letter, we clarify the implications of equilibrium food composition on consumer health outcomes by considering the simplest possible model to capture the central tradeoff between individual rents and collective health outcomes. Specifically, we abstract from product differentiation in the manufactured food sector and focus on incentives of food processors to choose cost-reducing inputs in a homogeneous product environment. ${ }^{3}$

Our main findings on manufactured food composition are as follows. First, we show that price competition between food processors leads firms to reduce cost by selecting unhealthy

\footnotetext{
${ }^{2}$ Pelman v. McDonald's Corp., 237 F.Supp.2d 512 (S.D.N.Y. Jan 22, 2003). Notably, McDonald's defense did not rest on their food being healthy; rather, they argued that if adding salt, sugar or other preservatives alters food composition in an unhealthy way, then virtually all processed food is altered in a similar manner, so that the health effect of consuming one product is indistinguishable from the health effect of consuming any other (Mello et al. 2003).

${ }^{3}$ Allowing food composition choices to alter the palatabililty of individual products would not alter the key results in the paper, but would provide additional modeling apperatus to sift through.
} 
food composition, even under circumstances where consumers are aware of the unhealthy content of manufactured food. Moreover, this problem is compounded in highly-competitive environments with a large number of food processors. Second, we demonstrate that taxes on manufactured food decrease the equilibrium health composition of manufactured foods whenever an improvement in the health status of consumers increases the price elasticity of food demand.

\section{The Model}

Consumer utility in the model, $U(Y, H)$, depends on manufactured food consumption, $Y$, and a measure of consumer health, $H$. Consumer health, in turn, depends on an index of manufactured food, $H\left(h_{1}, \ldots h_{i}, \ldots h_{n}\right)$, where $h_{i}$ denotes the healthiness of the manufactured food produced by food processor $i$ and $n$ is the number of firms. We interpret $h_{i}$ as any food composition decision by food processor $i$ that jointly affects the cost and the healthiness of manufactured food.

A key element in our analysis of food composition is that the demand for all consumer products depends on $H\left(h_{1}, \ldots h_{i}, \ldots h_{n}\right)$. This is the common property element of the model: The health composition choice of firm $i, h_{i}$, is mediated through the consumer market to affect the demand facing all food processors. ${ }^{4}$ One interpretation is that consumers receive periodic information on health, $H$, that revises demand for an entire category of manufactured food products, for instance in response to a doctor's warning. ${ }^{5}$

Consumer utility in our homogeneous product framework is $U(Y, H)=U\left(\sum_{i} y_{i}, H\left(h_{1}, \ldots h_{i}, \ldots h_{n}\right)\right)$, where $y_{i}$ is the output of firm $i$ and $Y=\sum_{i} y_{i}$. We assume utility is concave $U_{Y} \geq 0, U_{H} \geq$ $0, U_{Y Y} \leq 0, U_{H H} \leq 0, U_{Y H} \geq 0 .{ }^{6}$

\footnotetext{
${ }^{4}$ Considerable evidence exists that the impact of food on health derives from the "whole diet", rather than from the consumption of any individual products (Kant 1996).

${ }^{5}$ For example, considerable evidence exists that consumers are uninformed of advised salt guidelines, unclear about how much salt they consume, and unsure about the precise connection between high salt intake and negative health impacts (Kenten et al. 2013, Newson et al. 2013). Similarly, in the case of saturated fat consumption, Griffith and O'Connell (2010) show that even consumers who intend to buy healthy foods or to manage their cholesterol do not appear to purchase a diet that is lower in saturated fat.

${ }^{6}$ Utility depends on manufactured food and an outside good, $m$. The utility function is additively sepa-
} 
To examine manufactured food composition, we allow individual food processors to choose the healthiness of their products, $h_{i}$. Healthier products are more expensive to produce, which we specify with the cost function $C\left(y_{i}, h_{i}\right)=c\left(h_{i}\right) \cdot y_{i}$, for firm $i$, where $c^{\prime}() \geq 0$ and $c^{\prime \prime}() \geq 0 \cdot^{7}$

Because we confine attention to a homogeneous product market, we abstract from all forms of product differentiation, including nutritional labeling. Accordingly, market demand for manufactured food depends only on the contribution of $h_{i}$ to $H\left(h_{1}, \ldots h_{i}, \ldots h_{n}\right)$. We show below that qualitatively similar outcomes emerge in a differentiated product framework.

\subsection{Social Provision}

Given the cost function above, we consider without loss of generality the case of $n=1$, which results in the social planner's problem:

$$
\max _{\{Y, h\}} U(Y, H(h))-c(h) Y .
$$

The social optimum is characterized by the first-order necessary conditions

$$
\begin{gathered}
U_{Y}-c(h)=0, \\
\frac{U_{H}}{Y}=c^{\prime}(h) .
\end{gathered}
$$

Note that we assume without loss of generality that $\frac{\partial H}{\partial h}=1$.

At the social optimum, the quantity of manufactured food is selected to equate the marginal benefit with the marginal cost of consumption in equation (1). The healthiness of manufactured food is selected to align the marginal utility of health per unit of consumption with the marginal cost of providing healthy food composition in equation (2). Let $Y^{*}$ and $h^{*}$ denote the socially optimal solution that solves equations (1) and (2).

rable, $V=U()+m$, and we normalize the price of $m$ to unity.

${ }^{7}$ While it is clear that not all cost-reducing changes in food composition are also unhealthy changes in food composition, our focus here is on the interesting case in which a trade-off exists in food processors' choices of food composition between healthiness and cost. 


\subsection{Market Provision}

Now consider food processors that compete in an $n$-firm Cournot oligopoly market. Inverse demand for the manufactured food product is given by

$$
P\left(\sum_{i} y_{i}, H\left(h_{1}, \ldots h_{n}\right)\right)=U_{Y}(Y, H)
$$

and, given consumer demand, food processor $i$ solves:

$$
\max _{\left\{y_{i}, h_{i}\right\}} \pi_{i}=\left[P\left(\sum_{i} y_{i}, H\left(h_{1}, \ldots h_{n}\right)\right)-c\left(h_{i}\right)\right] y_{i}
$$

Maximizing profit results in the following first order necessary conditions:

$$
\begin{gathered}
\frac{\partial \pi_{i}}{\partial y_{i}}=P+y_{i} P_{Y}-c\left(h_{i}\right)=0 \\
\frac{\partial \pi_{i}}{\partial h_{i}}=\left[P_{H} \frac{\partial H}{\partial h_{i}}-c^{\prime}\left(h_{i}\right)\right] y_{i}=0,
\end{gathered}
$$

where $P_{Y}=U_{Y Y}$ and $P_{H}=U_{Y H}$.

Expression (3) is the standard oligopoly pricing condition that marginal revenue equals marginal cost. Expression (4) equates the marginal cost of healthiness with the marginal contribution of healthiness to manufactured food demand. Food processor $i$ 's choice of food composition impacts demand for manufactured food according to the product of two components: $(i)$ the marginal valuation of health to consumers, $P_{H}$; and $(i i)$ the contribution of an individual processors's choice of health composition to the consumer's overall health, $\frac{\partial H}{\partial h_{i}}$.

In the $n$-firm symmetric market equilibrium, $y_{i}=y=Y / n$ and $h_{i}=h$, and it follows that $\frac{\partial H}{\partial h_{i}}=\frac{1}{n} \cdot{ }^{8}$ The private market equilibrium in the symmetric case is completely characterized by

$$
U_{Y}+y U_{Y Y}=c(h) \Leftrightarrow \frac{U_{Y}-c(h)}{U_{Y}}=\frac{1}{n \varepsilon},
$$

\footnotetext{
${ }^{8}$ To show this result formally, consider the social welfare problem with $n>1$. The socially-optimal health level, $h_{i}^{*}$, now solves $U_{H} \frac{\partial H}{\partial h_{i}}-c^{\prime}(h) y_{i}=0$. In the symmetric equilibrium, $y_{i}^{*}=Y^{*} / n$ and $h_{i}^{*}=h^{*}$, it follows immediately from inspection that $\frac{\partial H}{\partial h_{i}}=\frac{1}{n}$.
} 


$$
\frac{1}{n} U_{Y H}=c^{\prime}(h)
$$

where $\varepsilon=-\frac{U_{Y} Y}{U_{Y Y}}$ is the price elasticity of demand for manufactured food. The first condition is the standard oligopoly condition that the Lerner index of market power equal to one over the share-weighted elasticity of demand. When $n$ is large, the quantity distortion in the market equilibrium vanishes (conditional on health), and price approaches marginal cost in the market equilibrium.

The second condition defines the private incentive to provide healthy manufactured food composition. In the monopoly case $(n=1)$, a food processor would set the marginal cost of health, $c^{\prime}(h)$, equal to the marginal valuation of health in consumer demand. Because the social planner considers the marginal utility of health per unit of demand, $U_{H} / Y$, rather than the marginal value of health in demand, $U_{Y H}$, the equilibrium food composition under monopoly embodies the familiar quality distortion first described by Spence (1975).

Oligopoly markets introduce novel effects on the health composition of manufactured food. When $n>1$, the individual food processor equates the marginal cost of healthy food composition with the share-weighted marginal valuation of health in consumer demand, $\frac{1}{n} U_{Y H}$, de-emphasizing the effect of healthy food composition on consumer demand. That is, each food processor fully internalizes the effect of unhealthy food composition on reducing production cost, but fails to consider the impact of the resulting consumer health impact on the profits of his $n-1$ rivals.

It is clear by inspection that the problem of unhealthy food composition worsens with the number of food processors in the market. Under perfect competition in the manufactured food industry $(n \rightarrow \infty)$, food processors face strong market pressure to reduce cost, $h_{i}$ accordingly tends to zero, and $P^{c}=c(0)$. In this case, the price of manufactured food decreases below the socially optimal price, $P^{*}=c\left(h^{*}\right)>P^{c}$, for all $h^{*}>0$. Manufactured food becomes relatively inexpensive in the private market, not because scale economies and technological change reduce the cost of processed food (as in Lakdawalla and Philipson 2009), 
but because aggressive price competition forces firms to decrease unit production costs by selecting less healthy food composition.

Before turning to examine the effect of tax policy, it is helpful to verify that the outcomes described here for the homogeneous product case are qualitatively similar to those which would arise with differentiated products. With differentiated products, food processor $i$ faces demand given by $P^{i}\left(y_{1}, \ldots, y_{n} ; H\left(h_{1}, \ldots, h_{n}\right)\right)$, where demand for product $i$ depends on individual product characteristics (e.g., flavor and taste) as well as on the health status of consumers. Food processor $i$ solves

$$
\max _{\left\{y_{i}, h_{i}\right\}} \pi_{i}=\left[P^{i}\left(y_{1}, \ldots y_{i}, \ldots y_{n} ; H\left(h_{1}, \ldots h_{n}\right)\right)-c\left(h_{i}\right)\right] y_{i}
$$

which results in the first-order condition for health of

$$
P_{H}^{i} \frac{\partial H}{\partial h_{i}}=c^{\prime}\left(h_{i}\right)
$$

With differentiated products, $\frac{\partial H}{\partial h_{i}}>0$ no longer need equal $1 / n$. Nevertheless, as in the homogeneous product case, each food processor ignores the impact of his food composition choice on the demand facing rival food processors when choosing health composition. Specifically, individual food processors consider only the effect of healthy food composition

on their own demand, $P_{H}^{i} \frac{\partial H}{\partial h_{i}}$, while a social planner would consider the impact of healthy food composition on the demand for all manufactured food products, $\left(P_{H}^{i}+\sum_{j \neq i} P_{H}^{j}\right) \frac{\partial H}{\partial h_{i}}$. Thus, a qualitatively similar outcome emerges in the differentiated products case whenever the choice of firm $i$ to provide healthier food composition increases the demand for rival food products, $\sum_{j \neq i} P_{H}^{j}>0$.

\section{Tax Policy}

In this section we consider the implications of tax policy for manufactured food composition. Our model is comprised of two distortions in the private market equilibrium: $(i)$ firms have insufficient incentives for healthy food composition; and (ii) firms restrict output to increase price-cost margins. In general, policies that attain a socially optimal resource allocation 
require the use of two instruments, for instance a minimum quality standard on healthiness, $h \geq h^{*}$, combined with a subsidy on output to align $y^{c}$ with $y^{*}{ }^{9}$ Nevertheless, given the large number of nutrients that contribute to consumer health outcomes, and the wide variety of food composition choices available to food processors, such policies are likely to be impractical.

An important food policy that is often considered to improve consumer health is a tax on manufactured food. For example, several countries have levied taxes on sugar-sweetened beverages.

Let $t$ denote a unit tax on manufactured food. The first order conditions in the symmetric market equilibrium are:

$$
\begin{gathered}
P+\frac{Y P_{Y}}{n}-c(h)-t=0, \\
\frac{1}{n} P_{H}-c^{\prime}(h)=0 .
\end{gathered}
$$

To characterize the implications of the tax on manufactured food output, prices, and health composition, we impose the standard oligopoly stability condition (Vives 2001)

$$
\varpi \equiv P_{Y}+y P_{Y Y}<0
$$

and differentiate equations (5) and (6) to get

$$
\left[\begin{array}{cc}
P_{Y}+n \varpi & \left(\frac{n-1}{n}\right) P_{H}+y P_{Y H} \\
P_{Y H} & \frac{1}{n} P_{H H}-c^{\prime \prime}
\end{array}\right]\left[\begin{array}{l}
\partial y \\
\partial h
\end{array}\right]=\left[\begin{array}{l}
1 \\
0
\end{array}\right] \partial t
$$

where we have substituted terms from equation (6). Letting $\Delta>0$ denote the determinant of the coefficient matrix, the effect of the tax on manufactured food output and health composition is

$$
\begin{aligned}
\frac{\partial y}{\partial t} & =\frac{1}{\Delta}\left(\frac{1}{n} P_{H H}-c^{\prime \prime}\right)<0, \\
\frac{\partial h}{\partial t} & =\frac{-P_{Y H}}{\Delta} \lessgtr 0 .
\end{aligned}
$$

\footnotetext{
${ }^{9}$ There have been some attempts to implement minimum quality standards for specific nutrients in products, for instance salt in the UK and trans fatty acids in the US.
} 
Taxes on manufactured food have the intended effect of reducing manufactured food consumption, but have an ambiguous effect on food composition. Specifically, when an increase in consumer health raises the price elasticity of food demand, $P_{Y H}>0$, that is when healthier consumers respond to lower food prices with larger increases in food consumption than unhealthy consumers, taxes on manufactured food result in a decrease in the health composition of manufactured food. The reason is that food taxes decrease the total quantity of manufactured food produced by firms, reducing the marginal benefit of providing healthier food composition in equation (6) when $P_{Y H}>0$.

\section{Conclusion}

In this paper we have examined market incentives for the health composition of manufactured food. Our findings have several implications for food policy. First, supply-side policies such as minimum quality standards and taxes on product attributes (e.g., fat, sugar, energy density) need to account for endogenous responses in equilibrium food composition. As Cawley (2015) observes, there is no specific subset of foods that cause health problems in consumers, so that proposed taxes on energy-dense foods run the risk that consumers switch to untaxed, energy-dense items (Chouinard et al. 2007; Fletcher et al. 2010, 2013; Zhen et al. 2014). Our model reveals that food processors have market incentives to modify the composition of manufactured food products in response to taxes.

Second, to the extent that consumer health outcomes are determined by supply-side decisions on food composition, food policies are likely to alter both the quantity and quality of manufactured food. For example, a tax on manufactured food that raises manufactured food prices can create a trade-off in consumer health implications between the beneficial effect of shifting consumption from manufactured food towards healthier, untaxed food products, and the adverse effect of reducing the health composition of manufactured food.

Third, our findings have empirical implications for assessing the consumer health implications of food policy. Public policies such as taxes on unhealthy food products lead 
both to lower consumption of these products and to healthier composition of these products whenever improved consumer health outcomes reduce the price elasticity of food demand, whereas adverse implications emerge for the effect of taxes on the health composition of food whenever improved consumer health outcomes increase the price elasticity of food demand.

An interesting extension of our research would be to consider food policies that target sequential stages of production and distribution of manufactured foods. Food policy in a manufactured food sector can be levied at both the manufacturing and retailing levels of the food system, which can provide potentially interesting incentives for healthy food composition. For example, while individual food processors produce only a small share of the manufactured food in consumers' diets (Slining et al. 2013), supermarkets sell virtually all manufactured foods. An interesting extension to our model would be to examine the role for supermarkets to internalize health effects of consumers at the shopping-basket level though food policy levied at sequential manufacturing and retail stages of the food system. 


\section{References}

[1] Cawley, J., 2015. An economy of scales: A selective review of obesity's economic causes, consequences, and solutions. Journal of Health Economics 43, 244-268.

[2] Chouinard, H.H., Davis, D.E., LaFrance, J.T., Perloff, J.M., 2007. Fat taxes: big money for small change. Forum for Health Economics \& Policy 10, Article 2.

[3] Drewnowski, A., Darmon, N., 2005. The economics of obesity: dietary energy density and energy cost. The American Journal of Clinical Nutrition, 82(1), 265S-273S

[4] Fletcher, J.M., Frisvold, D., Tefft, N., 2010. The effects of soft drink taxation on softdrink consumption and weight for children and adolescents. Journal of Public Economics 94, 967-997.

[5] Fletcher, J., Frisvold, D., Tefft, N., 2013. Substitution patterns can limit the effects of sugar-sweetened beverage taxes on obesity. Preventing Chronic Disease 10,120-195.

[6] Griffith, R., O'Connell, M., 2010. Public policy towards food consumption. Fiscal Studies 31(4): $481-507$.

[7] He, F., MacGregor, G., 2009. A comprehensive review on salt and health and current experience of worldwide salt reduction programmes. Journal of Human Hypertension $23,363-384$.

[8] Kant, A., 1996. Indexes of overall diet quality: A review. Journal of the American Dietetic Association 96 (8), 785 - 791.

[9] Kenten, C., Boulay, A., Rowe, G., 2013. Salt: UK consumers' perceptions and consumption patterns. Appetite 70, 104-111.

[10] Lakdawalla, D., Philipson, T., 2009. The growth of obesity and technological change. Economics and Human Biology 7, 283-293. 
[11] Mello, M., Rimm, E., Studdert, D., 2003. The Mclawsuit: the fast-food industry and legal accountability for obesity. Health Affairs 22 (6), 207-216.

[12] Monteiro, C.A., 2009. Nutrition and health. The issue is not food, nor nutrients, so much as processing. Public Nutrition Health, 12(5), 729-731.

[13] Moorman, C., Ferraro, R. and Huber, J. (2012). Unintended nutrition consequences: firm responses to the nutrition labeling and education act. Marketing Science 31(5), $717-737$.

[14] Moubarac, J-C., Martins A.B., Claro, R.M., Levy R.B., Cannon G., Monteiro C.G., 2013. Consumption of ultra-processed foods and likely impact on human health. Evidence from Canada. Public Nutrition Health, 16(12), 2240-2248.

[15] Newson, R., Elmadfa, I., Biro, G., Cheng, Y., Prakash, V., Rust, P., Barna, P., Lion, R., Meijer, G., Neufingerl, J., Szabolcs, I., van Zweden, R., Yang, Y., Feunekes, G., 2013. Barriers for progress in salt reduction in the general population. An international study. Appetite 71, 22-31.

[16] Slining, M. M., Ng, S. W. and Popkin, B. M. (2013). Food companies' calorie-reduction pledges to improve US diet. American Journal of Preventive Medicine 44(2), 174-184.

[17] Spence, M. A., 1975. Monopoly, quality, and regulation. Bell Journal of Economics 6 (2), $417-429$.

[18] Unnevehr, L. J., Jagmanaite, E., 2008. Getting rid of trans fats in the US diet: Policies, incentives and progress. Food Policy 33 (6), 497 - 503.

[19] Vives, X., 2001. Oligopoly pricing. Old ideas and new tools. MIT Press, Cambridge, USA.

[20] Warner M. 2013. Pandora's Lunchbox. How processed food took over the American meal. Scribner: New York. 
[21] Zhen, C., Finkelstein, E.A., Nonnemaker, J.M., Karns, S.A., Todd, J.E., 2014. Predicting the effects of sugar-sweetened beverage taxes on food and beverage demand in a large demand system. American Journal of Agricultural Economics 96 (1),1-25. 